\title{
Studying the priority of technical-tactical actions fulfillment among highly-qualified belt wrestlers during competitive activity
}

\author{
Gabdyzhalil Suleimanov", Yuri Boltikov, Oleg Solomahin, Ilya Zemlenukhin, Aleksei Kaplev \\ Volga Region State Academy of Physical Culture, Sports and Tourism, 420010, Kazan, Russia
}

\begin{abstract}
Dynamically developing kind of sport "Belt wrestling" undergoes serious changes nowadays in the structure of competitive combats and it makes specialists study combats and search for new ways of improving the forms and content of wrestlers' technical and tactical training. This article studies an urgent question of techniques fulfillment priority by highly-qualified belt wrestlers in the final combats of the biggest International competitions. From the held analysis of 48 combats among belt wrestlers during the final part of three World Cups and three World Championships among 18-20 year-old juniors we define 6 most frequently used techniques. They were used by the winners of the competitions. The article also presents detailed analysis of the held technical-tactical actions indices during the combat and the received for them points among highly-qualified wrestlers. It was stated that highly-qualified belt wrestlers have a wide arsenal of technical means for an effective fulfillment of technical-tactical actions during important combats. At the same time, we underline that in the held by them combats attacking and executing a counterattack actions prevail and wrestlers organize the combat in power oriented, aggressive and attacking manner.
\end{abstract}

\section{Introduction}

Belt wrestling is a special in its beauty and technical-tactical diversity kind of competitive combats. It exists from ancient times, as one of the main means of struggle for life among people. From ancient times belt wrestling provided physical development of strong men and brave warriors.

The considered in the article kind of sport, as a kind of wrestling, originated in ancient times among Turkic people. Having gone through a long way of development from a form of entertainment belt wrestling is very popular nowadays among many nations of the world, being the main kind of competitions at national events and a part of the national culture. Belt wrestling is a spectacular kind of combats and its rules are simple and can be understood by everybody. Wrestling attracts people of different age as it is spectacular and keeps in suspense and gives energy. This kind of combat is the image of a healthy and powerful nation.

This kind of combat has different kinds. Taking into account the community and differences in the technique and tactics of combat carrying out, for national and International competitions organization, general rules of competitions were created. In generally adopted rules national traditions and also the conditions of modern International rules of sports combat were taken into consideration. The main principle, which is the base for general gules, is the following: it is permitted to use any techniques (apart from anti-articular and suffocating technique) from a mutual stand with a belt hold with a simultaneous prohibition to hit the opponent. This peculiarity increases the arsenal of wrestling techniques, makes it dynamic, decreases traumatism, helps wrestlers from other kinds of single combats take part in competitions and take belt wrestling into a higher International level [2].

A positive tendency of this kind of sport development during recent years caused the following changes in competitive combat content. The process of combat became more active and aggressive. It demanded changes in the methodology of training highly-qualified athletes. The priority for the wrestlers became quick technical-tactical objectives solution, connected with effective attacking combinative techniques use. This tendency of training highlyqualified wrestlers is mentioned by the leading specialists in this kind of sport. They underline that the existing methodologies of training don't take into account the demands of modern wrestling. As a result, it has a negative influence on the wrestlers' sportsmanship improvement and makes specialists search for the new ways of forms and content development of technical and tactical training among highly-qualified athletes, paying attention to an effective and timely fulfillment of the attacking and executing counterattack actions during a competitive combat $[3,6,7]$.

Earlier by means of competitive combats analysis we revealed that different and effective technical-tactical actions (TTA) fulfillment by a belt wrestler was the main index. It conditioned his success during the competitions. Methodical

\footnotetext{
${ }^{*}$ Corresponding author: gabdyjalil@yandex.ru
} 
support of a wrestler's training demands, first of all, more effective TTA and their improvement. It provides techniques integration from other kinds of single combats. They are similar in TTA structure with belt wrestling technique $[1,4,8]$.

\section{Materials and methods}

We organized pedagogical observation over competitive activity of highly-qualified belt wrestlers. We analyzed belt wrestling International competitions: 3 World Cups (2017, 2018 and 2019) and 3 World Championships (2017, 2018 and 2019) among juniors. 48 combats were analyzed among athletes-winners of the final combats $\left(1^{\text {st }}\right.$ place combats). Weight categories were divided into three groups: light weight $(57 \mathrm{~kg}, 62 \mathrm{~kg})$, average category $(68 \mathrm{~kg}, 75$ $\mathrm{kg}, 82 \mathrm{~kg}$ ), heavy category (90 kg, $100 \mathrm{~kg}$, more than $100 \mathrm{~kg}$ ).

The following research methods were used: scientific-methodical sources analysis, pedagogical observation, competitive activity video analysis, mathematical statistics.

\section{Research results and Discussion}

For the research we created the tables, which presented priority analysis of techniques fulfillment by highlyqualified belt wrestlers (Table 1), and the average indices of technical-tactical actions fulfillment and the points for the combat among the examined athletes (Table 2).

Table 1 presents priorities analysis of techniques during competitive activity of the final combats winners during important competitions. 6 frequently used among belt wrestlers techniques were revealed:

- $\quad$ standing hanks-52 times;

- $\quad$ hip throws (hip) - 35 times;

- $\quad$ covering - 23 times;

- $\quad$ leg pick-up throw - 6 times;

- $\quad$ inside bend of knee pick-up throw- 5 times;

- counter-holds -65 times.

Table 1. Priority analysis of techniques fulfillment by highly-qualified belt wrestlers

\begin{tabular}{|l|c|c|c|c|c|}
\hline \multirow{2}{*}{ Techniques } & \multicolumn{3}{|c|}{ Weight groups } & \multirow{2}{*}{$\%$} \\
\cline { 2 - 5 } & Light & Average & Heavy & & \\
\hline Hip throws (hip) & 5 & 14 & 16 & 35 & 18,6 \\
\hline Standing hank & 15 & 29 & 8 & 52 & 27,6 \\
\hline $\begin{array}{l}\text { Inside bend of knee pick-up } \\
\text { throw }\end{array}$ & 2 & 2 & 1 & 5 & 2,6 \\
\hline Leg pick-up throw & 3 & 2 & 1 & 6 & 3,1 \\
\hline Covering & 7 & 7 & 9 & 23 & 12,2 \\
\hline Pendulum & 1 & 1 & & 2 & 1 \\
\hline Counter-hold & 22 & 27 & 17 & 65 & 34,5 \\
\hline Total amount of techniques & 55 & 82 & 52 & 188 & 100 \\
\hline Ahead of time & 9 & 17 & 15 & 41 & \\
\hline
\end{tabular}

As a result of the held research we revealed that the mentioned techniques of belt wrestling are the most frequently used, with the help of which wrestlers managed to win 41 combats ahead of time. Priority of techniques study helps to reveal techniques, which wrestlers stop using or use not very often. For example, belt wrestlers stop using such technique as "Pendulum", because this technique fulfillment can cause covering from the side of the opponent.

Covering is understood as a defensive action of an opponent, when the athlete, who is sheltering, can see the direction of the attacking action and react, organize counter-attack and fix the opponent on his back. Pendulum is a technique when the opponent is lifted off the mat. For "Pendulum" technique it is necessary to make a misleading throw movement to the right or to the left in order to make the opponent put both legs on one side for defense and then use a technique throwing the opponent in front of oneself $[5,9]$.

During competitive activity analysis among belt wrestlers we revealed that light, average and heavy weight wrestlers use almost the same techniques, but there are some differences:

- light weight wrestlers effectively use leg pick-up throws-5 times, standing hanks-15 times, hip throws (hip)-5 times, pendulum once;

- $\quad$ average weight wrestlers use the following techniques: standing hanks-29 times, hip throws-14 times, leg pick-up throws-4 times, pendulum throws-once and most of all among weight categories they use counter-hold- 27 times;

- $\quad$ heavy weight wrestlers use the following techniques: hip throws- 16 times, standing hanks -8 times, leg pick-up throws -2 times and most of all they use covering -9 times.

It should be noted that the average weight belt wrestlers have most of all ahead won combats- 17 , heavy weight wrestlers-15 and light weight wrestlers- 9 ahead won combats. 
One of the important effectiveness indices of the held combat is the amount of the realized technical-tactical actions during the combat and the received points for them.

Table 2 presents the indices of the held technical-tactical actions during the combat and the received points for them.

Table 2. The indices of the held technical-tactical actions during the combat and the received points for them among highlyqualified belt wrestlers

\begin{tabular}{|c|c|c|c|}
\hline \multicolumn{2}{|c|}{ Weight categories } & TTA during the combat & Points for the combat \\
\hline \multirow{3}{*}{ Light } & $57 \mathrm{~kg}$ & 3.8 & 5,1 \\
\cline { 2 - 4 } & $62 \mathrm{~kg}$ & 5,3 & 7,8 \\
\hline \multirow{3}{*}{ Average } & $68 \mathrm{~kg}$ & 3,8 & 8,1 \\
\cline { 2 - 4 } & $75 \mathrm{~kg}$ & 4,1 & 7,3 \\
\cline { 2 - 4 } & $82 \mathrm{~kg}$ & 6 & 7,5 \\
\hline \multirow{7}{*}{ Heavy } & $90 \mathrm{~kg}$ & 4,8 & 7 \\
\cline { 2 - 4 } & $100 \mathrm{~kg}$ & 3,1 & 6,5 \\
\cline { 2 - 4 } & More than 100 & 2,1 & 5 \\
& $\mathrm{~kg}$ & & \\
\hline
\end{tabular}

Table 2 shows that the highest index of TTA during the combat (6 times) was among wrestlers with weight category $82 \mathrm{~kg}$, in terms of the gathered points within the combat 7,5 points for an athlete. The lowest index of technical-tactical actions was among belt wrestlers with weight category $100 \mathrm{~kg}(3,1)$ and more than $100 \mathrm{~kg}(2,1)$, in terms of the received points 6,5 and 5 points for an athlete.

Competitive activity analysis among belt wrestlers according to weight categories showed that the most effective technical-tactical actions were among the average weight wrestlers $-68 \mathrm{~kg}, 75 \mathrm{~kg}, 82 \mathrm{~kg}$.

Pictures 1 and 2 present the indices of the held technical-tactical actions during the combat and the received for them points among highly-qualified belt wrestlers.

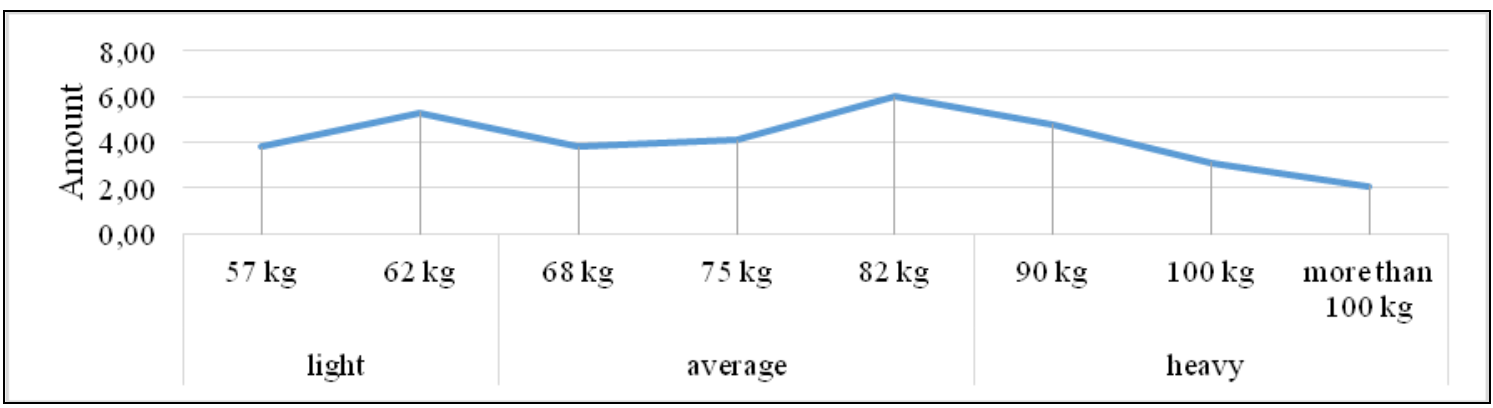

Fig. 1. Indices of technical-tactical actions use during one combat according to weight categories

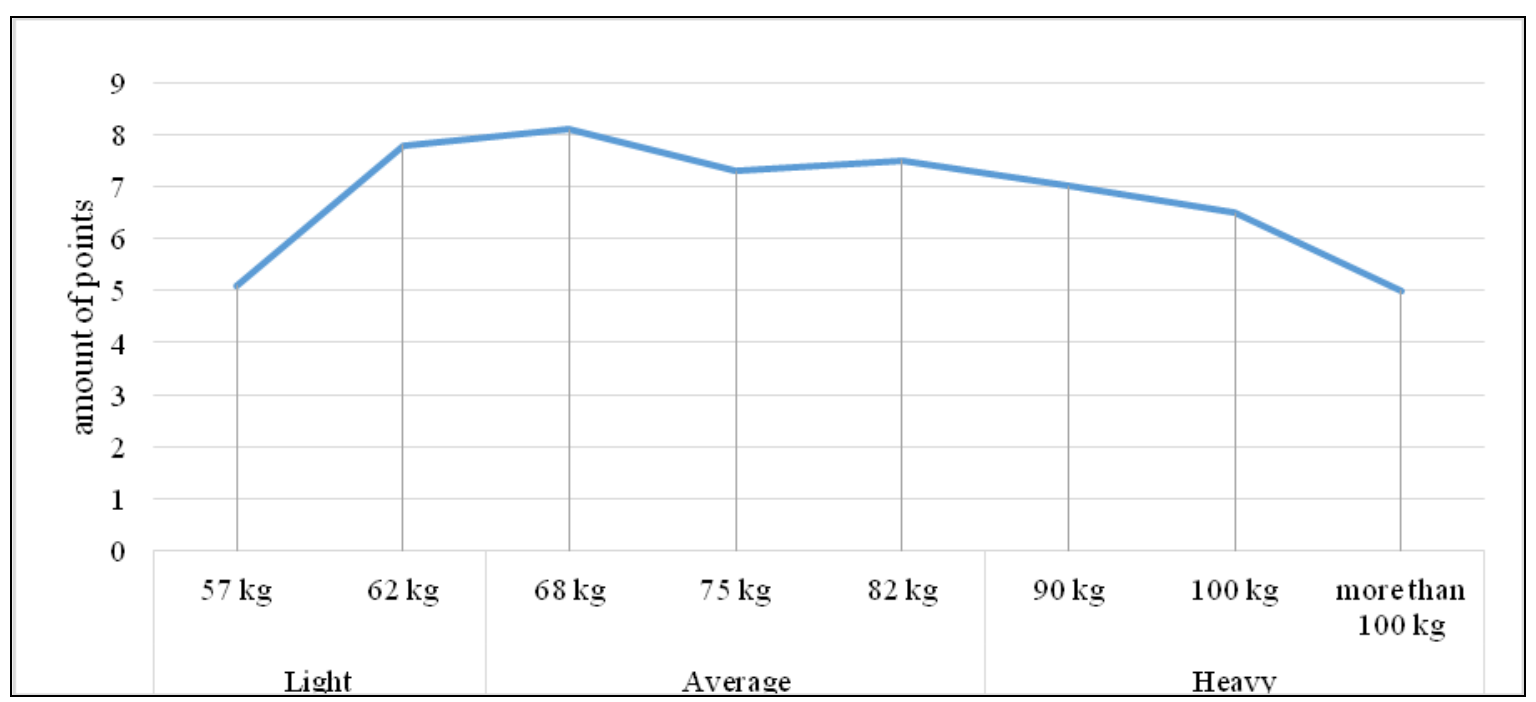

Fig.2. The received points during one combat according to weight categories

Fig. 1 shows that the indices of the held technical-tactical actions during the combat according to different weight categories have a sinuous dynamics. It should be noted that picture 1 helps to see quick decrease of technical-tactical actions within one combat during the transfer from a light weight category to the average one.

Fig. 2 shows that there is gradual points distribution for technical-tactical actions fulfillment depending on their weight category. It is interesting that weight categories $57 \mathrm{~kg}$ and more than $100 \mathrm{~kg}$ have almost the same points for a combat. The picture also shows that the highest index of the received points during the combat is among weight 
category $68 \mathrm{~kg}$. It proves that wrestlers of this category chose mostly attacking tactics of combat using the most effective techniques, which leads to effective technical-tactical actions.

Thus, during competitive activity analysis among highly-qualified belt wrestlers it was revealed that the choice of these or that technical-tactical actions is conditioned by their style of combat organization. It should be noted that most respondents have the attacking style of combat. Highly-qualified wrestlers used all techniques after a thorough training and only if a wrestler sees favorable condition for their effective realization, preserving concentration during the whole combat (4 minutes).

\section{Conclusions}

The held analysis of competitive activity among highly-qualified belt wrestlers helped to specify the priority of techniques choice, which combatants effectively used during the combats held in terms of important competitions: standing hanks, hip throws, leg pick-up throws, coverings and counter-attacks. It was stated that heavy weight wrestlers used simple techniques more frequently (such as coverings) and hip throws. Light weight wrestlers have smaller arsenal of techniques, than the average weight wrestlers. However, the average weight wrestlers most of all use standing hanks.

Competitive activity analysis among highly-qualified belt wrestlers showed that the greatest arsenal of technicaltactical actions within one combat was among wrestlers of the following weight categories $82 \mathrm{~kg}, 62 \mathrm{~kg}, 90 \mathrm{~kg}$ and it shows that in this weight categories combats are especially dynamic and aggressive. Nowadays belt wrestling becomes "spectacular", wrestlers demonstrate power oriented, aggressive struggle during each combat and attract audience.

\section{References}

1. K. Ananchenko, Slobozhanski scientific-sports bulletin 6, 74-76 (2003)

2. G. Suleymanov, I. Zemlenukhin, E. Burtseva, Tula State University proceedings. Physical culture. Sport 5, 74-80. (2019)

3. Yu. Tropin, N. Boychenko, Slobozhanski scientific-sports bulletin 2(40), 117-120 (2014)

4. Yu. Tropin, V. Romanenko, V. Ponomarev, Slobozhanski bulletin of science and sport 3, 205-209 (2016)

5. A. Kuznetsov, Yu. Shulika, Theoretical basis and methodology of mastering the technique and tactics of belt wrestling, 264 (2010)

6. E. Sandberg, Human Kinetics (2007).

7. Yu. Boltikov, O. Solomakhin, I. Konovalov Theory and practice of Physical Culture, 5, 102-104 (2018)

8. I. Konovalov, A. Nurmukhametov, Yu. Boltikov, O. Solomahin, Human Sport Medicine 19(1), 65-71 (2019)

9. A.S. Kuznetsov, S.V. Novakovskiy, O.B. Solomakhin, The Russian Journal of Physical Education and Sport, 13(1), 16-26 (2018) 